\title{
The Effect of Using Multi-Skilled Workforce on the Flexibility of Project Resource Scheduling and
} Project Costs

\author{
Thulisile Manyi, Rosemary Sibanda, Ankit Katrodia \\ University of KwaZulu-Natal, Durban, South Africa \\ Tulisile.Manye@gmail.com, Sibanda@ukzn.ac.za, KatrodiaA@ukzn.ac.za
}

\begin{abstract}
The introduction of multi-skilling within organisations is normally conducted with the aim of improving efficiency, quality, production and cost-effectiveness. The study addressed the effect of using multiskilled workforce in the execution of project activities by studying the changes in project execution resource scheduling flexibility and project costs in response to workforce multi-skilling strategy. A quantitative research design was used, to test the concept of workforce multi-skilling to predict its influence on project resource scheduling, project cost saving, project duration, effect on optimal utilization of project technicians and members if adopted at Eskom PTM Central Group department. An electronic questionnaire was distributed to collect data and statistical analysis of data was conducted. The hypothesis testing performed concluded as follows; H1: The use of multi-skilling provides for flexible project resource scheduling; the research hypothesis was accepted. H2: Multi-skilling has a positive effect on the project cost savings; the research hypothesis was rejected. H3: The use of multi-skilling has no significant impact on project duration; the research hypothesis was rejected. H4 (i): The findings show that a positive relationship between multi-skilling and job redesign exists, and H4 (ii): Multi-skilling therefore has a positive impact on the adoption of multi skills; both research hypotheses were accepted.
\end{abstract}

Keywords: Multi-skilling, flexible project scheduling, project costs, project duration, job redesign

\section{Introduction}

X PTM is a division of X Group Technology; a mandated critical technical service provider to predominantly X Generation, as well as a project associated technical services to X Group Capital, Transmission and Distribution. This business unit also offers engineering support services, commissioning and maintenance of Power Electronics, Electrical Protection, Automatic Voltage Regulators, Supervisory Control and Security Systems, Specialised Electrical Tests on Power Transformers, Electrical Calibration Services, Metering and Measurements, Industrial Air-conditioning and Electronic Card Repairs. X PTM has offices in Johannesburg, Durban, Cape Town, Bloemfontein, Klerksdorp and Witbank. Nowadays, business peak level performance greatly relies on the continuous development of human resource policies. For this reason, most organizations consider human resource labour as the most important aspect of production, as well as the most indispensable form of capital, the main source of competitive advantage and vital to normal operations of the organization. Accordingly, the most effective advancements to attaining competitive superiority in the current business environment are in the improvement of employee proficiency (Saravani \& Abbasi, 2013). It is only in developed countries that multi-skilling has been recorded as successful in carpentry and piping; crane operation and truck driving as a model to improve project labour cost, control project duration and reduce idle times between activities (Attia, Duquenne \& Le-Lann, 2013).

The increasing need for production companies to rapidly respond to market volatility is however consequential because it creates a strong demand for flexibility in the operational processes of business (Attia, et al., 2013). The concept of multi-skilling promises to bring about flexibility in operational processes in a win-win approach where the company reduces its overall labour costs and on the other hand the multi-skilled employee income increases (Saravani \& Abbasi, 2013). An effective well-targeted training aimed at multi-skilling of the workforce in production services can be a powerful force in addressing current skills shortages in manufacturing (Puttick, 2008). This research study aims to examine the effect of using multi-skilled workforce in the execution of project activities by studying the changes in project execution resource scheduling flexibility and project costs in response to workforce multi-skilling strategy and the use of job redesign to facilitate multi-skilling. The knowledge gaps identified in the literature review informs the purpose, research objectives, hypothesis and significance of the study. The major sources of information for this study range from published books', peerreviewed published journals, conference publications, periodic articles as well as newspaper articles. 


\section{Literature Review}

The database sources that were used were EBSCO host, Google Scholar, Science Direct and Emerald Insight. The selection of sources was based on the relevance of information to the topic under research, the credibility of the sources and year of publication. The introduction of workforce multi-skilling within organisations is typically carried out with the aim of improving efficiency, production, quality and costs reduction. Recent research reports that the majority of case study companies had used multi-skilling as part of their process of reorganisation (Horbury \& Wright, 2010). In a like manner, the quest by businesses and leaders to find ways to improve productivity and cost effectiveness has led many companies to the adoption of labour multi-skilling practice, where workers can work across traditional occupational boundaries (Adamu, Nensok \& Aka, 2012). The concept of multi-skilling arguably traces back in time to when mega structures like the Egyptian pyramid and the Great Wall of China were built (Nwaogazie, Augustine \& Henshaw, 2016). Presently, the world's financial system has undergone tremendous changes in recent years and the immense competition created has given rise to the three buzzwords in the business world that are; targets, deadlines and performance (Sushil, 2014).

As a result, global trends suggest that skills shortage is a worldwide occurrence; hence countries, states and businesses all over the world continuously express unhappiness regarding the shortage of skilled professionals in various sectors of their economies (Mateus, Allen-Ile, \& Iwu, 2014). The growing need for reaction to market volatility raises a strong demand for flexibility in organizational operations and call for businesses to develop strategies for short, medium and long-term in order to preserve and develop their workforce skills (Attia, et al., 2013). The most serious challenges confronting labour intense industries today is the limited access to the skilled workforce; seeing the increasing need for cost-effectiveness and productivity, some companies have already started using multi-skilling as a potential solution (Singh \& Shah, 2014). Also, the rise in competition levels across industries has made competence to be regarded critical or business to maintain the long-term competitive advantage. Subsequently, firms are forced to realize the need to develop innovative technical competency measures that warrant the use of multi-skilling; narrowly defined as utilization strategy where an employee possess a range of skills appropriate for more than one work process (Akinola, Ogunsemi \& Dada, 2015).

This means, organizations may introduce multi-skilling as support to business strategic changes aimed at improving efficiency, product quality, production rate and competitiveness, as well as cost effectiveness. The concept of multi-skilling allows firms the flexibility to reallocate labour resources in response to volatile industry demands (DeVaro \& Farnham, 2010). Multi-skilling as defined by Engineering Employers Federation (EEF) is the attainment of additional skills, complementing those previously acquired in a given job. In addition, multi-skilling is also referred to as means of removing traditional divisions separating disciplines in work areas and giving responsibility to individuals well trained for a range of different types of activities and multi-skilling has three dimensions; vertical, horizontal and depth multi-skilling, however in most situations a combination of all three is ideal (Singh \& Shah, 2014). Similarly, multi-skilled labour forces are workers who possess a range of skills that allow for participation in more than one work process (Gomar, et al., 2012). The database sources that were used were EBSCO host, Google Scholar, Science Direct and Emerald Insight. The selection of sources was based on the relevance of information to the topic under research, the credibility of the sources and year of publication.

Research Studies About the Concept of Multi-Skilling: The study by De Varo and Farnham (2010) to evaluate a product market volatility on a firm's choice between multi-skilling and skill specialization was conducted based on a theoretical model that captured trade-offs between multi-skilling (greater flexibility to schedule workforce in production) and specialization (which shapes workers to be experts in responding to product market signals in their area of specialty). The research by Irene (2009) to improve management strategies, decrease the mismatch between required and available skilled labour and to discuss the consequences of ignoring the interests of craftsmen. This quantitative study was conducted in the construction industry of Estonia, comparing multi-skilled to single skilled construction craftsman production outputs. The results analysis showed that no matter how volatile the construction project is, the composition of labour resources by trades is stable if an employer uses multi-skilling. Whereas for single-skilled labour resource 
overloads and idle time periods would be unavoidable. However, the study conducted in the construction industry and it did not focus on the engineering project execution work part of buildings construction work. $\mathrm{X}$ programme management division assists the organisation to effectively, track, steer and manage projects from a strategic, enterprise orientated perspective.

Measuring Project Delivery: The factors to consider when measuring project delivery success is a topic greatly debated by scholars, but it is generally agreed that for a project to be deemed successful, the project must be suitable for purpose and achieve all deliverables, however, time, cost and quality remain as central project management delivery targets (Brown, Adams \& Amjad, 2007). In contrary, traditional project management systems that entirely pursue success criteria of time, cost, quality and achieving technical requirements have been considered ineffective, with the shift focusing on multiple stakeholder expectations (Mir \& Pinnington, 2014). Even though, the success of a project depends on completion of work before due date, within the project budget and achievement of technical deliverables, to some cases these limits are circumvented to lessen scheduling pressures through the use of a technique called project activity crushing to help finish activities quicker and ultimately the project (Kim, Kang \& Hwang, 2012). Good to note is that, in business with flexible staff complement possessing multi-skills, planning of activities and project resource scheduling focuses on stakeholder needs than on staff capabilities (Rajendra, 2016). In line with the overall X business strategic objectives there is currently a need to improve on cost management in the form of cost containment, accurate projections and control over expenditure (Eskom, 2016). Objectively, programme management strives to enable the tracking of an aggregation of projects to oversee resource allocation, prioritize on-going investment decisions and track projects costs, schedule, risks and benefits as part of overall program management (Eskom, 2014).

Project Resource Scheduling and Cost: The use of labour workforce scheduling to correct overstaffing and or understaffing in the service industry across multiple projects is often challenged by lack of flexibility due to the exclusive use of specialist labour force (Henao, Munoz \& Ferrer, 2015). An organization with multi-skilled personnel enjoys flexible labour-force benefits which provide the employer ability to schedule and arrange the workforce to best suit the needs of the business (Rajendra, 2016). This section examines the impact of assigning multi-skilled employees to different activities, study schedule efficiency and measure implications on cost savings. Labour resource scheduling is a process of putting together a work timetable and assigns staff to activities accordingly to help meet organizational service demands. This involves determining the number of workers with certain skills needed to complete a specific project task. Consequently, this makes it extremely difficult to determine optimal solutions that minimise costs, meet workforce preferences, allocate activities equitably among labour resources and fulfil all the workplace constraints.

As a result, companies provide project managers with the decision tools, such as spreadsheet and database tools to help schedule the right employees at the right time and at the minimal cost while ensuring a high level of employee job satisfaction (Ernst, Jiang, Krishnamoorthy \& Sier, 2004). Meanwhile, the challenge with scheduling single skilled human resources is a well-known problem in project management, project scheduling with multi-skilled workforce is an extended problem due to the fact that this option requires a multi-skilled staff complement as it assumes that any resource can competently perform a project task that requires a range of skills (Zha \& Zhang, 2014). Similarly, the advantage to multi-skilled resource strategy is that of which each worker possesses multiple skills which allows them to participate in any activity that fits one of their skills and this has been proposed to improve project workforce resource scheduling and utilization (Jaskowski, 2013). However, assigning project work to human resources taking into account resource specific skills and efficiencies is a general planning task that has to be performed in any organisation (Heimerl \& Kolisch, 2010). For example, project resource scheduling in construction projects is mainly affected by unpredictable factors such as cash flow and design changes (Arunadhevi, 2016).

There are quite a number of different scheduling models established to reduce activity durations and hold-ups in projects, however most of these methods assume single skilled labour (Abotaleb, et al., 2014). For many years, the two approaches that have been proven to be useful in planning, scheduling and controlling construction projects have been the Critical Path Method (CPM) and the Project Evaluation and Review Technique (PERT) (Anon., 2015). However, research has shown that traditional scheduling techniques such as 
PERT and CPM are not suitable for handling linear projects (Liu \& Wang, 2012). Given the rapid advancements in computer technology, more heuristic algorithms are now available to deal with complex linear scheduling challenges involving work efficiency and resource task allocation (Liu \& Wang, 2012). These methods allow project managers more control of the schedule and to better estimate the early and late times at which activities can start and finish, calculate activity slack, outline critical activities, and assess the impact of changes in duration, logical relations and cost on the overall project duration (Render, et al., 2015).

Research Studies on Multi-Skilling, Project Scheduling and Cost: A study conducted by (Zha \& Zhang, 2014), to develop a model to address the project scheduling problem with multi-skilled worker, in which autonomous and induced learning are both considered, to help assist the project manager to determine the start time, the finish time, and resource scheduling for each activity, Moreover, combined with the total cost formulation, the project manager can balance the project make-span with the total cost. The results show that each level of induced learning corresponds to a combination of project make-span and total cost. By means of determining the level of induced learning, the project manager can balance them in project scheduling. However, the study was conducted in China as an experiment and was not focused to any industry. Lui and Yang (2011) created a model aiming at reducing total costs of the project through the use of multi-skilled labour. The model takes into consideration a number of variables not discussed in previous models such as the overtime cost and the number of skills per employee. Be that as it may, there was no strong validation provided by comparing the output with conventional techniques or rather actual projects as examples. Therefore, the success of multi-skilling strategy greatly relies on the project manager's ability to schedule workers to appropriate tasks and compose teams effectively.

Hence why, project managers still need to have important competencies in project scheduling and staffing of human resources, especially when facing the problem of labour resource skills constraints (Chan, 2014). Burleson, Haas, Tucker et al. (1998) made known to some multi-skilling strategies such as dual-skill strategy, four-skill strategy, four-skill-helpers strategy, and unlimited-skill strategy as means to prove the benefits of the multi-skilling concept. The four strategies were compared by comparing the economic benefit of each of them in a $\$ 70,000,000$ construction project. The findings were that the proposed multi-skilling strategies resulted in a reduction in project labour cost by 3\%-20\%. However, the mechanism for selecting the best strategy for a given project was not developed. Henao, Muñoz and Ferrer (2015) conducted a study on the impact of multiskilling on personnel scheduling in the service sector; a retail case. The study compared the impact of using multi-skilled resources to specialist resources on the efficiency of the schedule. The results showed that multiskilled personnel may be a cheaper option compared to hiring part-time specialized staff, however depending on the cost of training required to upskill staff and therefore a balance between multi-skilling and the part-time specialist contract was found to be desirable in the retail sector.

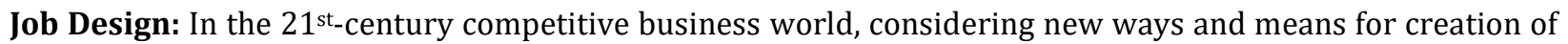
organizational efficiency is inevitable, given the rapid changes in the external business environment resulting to huge impacts to internal operations (Saravani \& Abbasi, 2013). For example, the demand to satisfy customers, regulators, skilled workers, social activists and shareholders increase pressure on businesses to deliver excellent performance while maintaining diverse stakeholder needs at the same time (Tarus, 2014). Therefore, a new method of job design is necessary to motivate managers to adjust to changes presented by business environment, technological advancements, shareholder needs and workforce motivation. Job rotation is one of the most effective methods for empowering human resource (Saravani \& Abbasi, 2013). Job rotation means a planned out reshuffling of human resource labour between jobs for a period of time with the aim of cross-skilling, ensuring job independence and increasing employee motivation (Saravani \& Abbasi, 2013). Job rotation is particularly the product of Japanese companies' employment policies to ensure the attainment of knowledge and skills which help workers adapt to changes in technology and in the process improving the value of the employees in labour market (Kaymaza, 2010). Furthermore, when businesses provide the workforce with a large amount of firm-specific human capital, those workers become less subject to poaching by other companies, thus reinforcing returns on training investments made by the firm through job rotation (Morita, 2005). Job redesign and rotation enhances the productivity of human resource labour and increases level of performance for both the company and employees, because multi-skilling employees through on job training and classroom; creates a logical and effective interface between skills attainment and employee 
motivation (Saravani \& Abbasi, 2013). Furthermore, with multi-skilling adoption, employees enjoy crossfunctional training to increase skills competency and at the same time organizations enjoy increasing talent pool, thus labour force resource availability (Srinivasan, 2014). Additionally, some organizations brag about bigger spending each quarter on training and development of new skill-sets to improve resource competence and availability to perform more job processes. Noteworthy, key to the concept of multi-skilling is formal acknowledgement and encouragement of knowledge sharing amongst employees (Srinivasan, 2014).

Research Studies on Job Rotation and Performance: Past similar studies by (Saravani \& Abbasi, 2013) attempted to investigate the effects of job rotation patterns on the performance of employees considering the skill diversity and job satisfaction and providing effective guidelines to enable managers to lead the organization toward a better future by desired policies and the results showed that Job rotation positively influences job performance mediated by job satisfaction and skill variation. However, the study was conducted in the banking industry and it did not consider project resource scheduling. A study by Mossa, Boenzi, Digiesi, Mummolo and Romano (2016) proposed a model which aimed at finding optimal job rotation schedules in work environments characterized by low load manual tasks with a high frequency of repetition. The model is a mixed integer programming model allowing for the maximization of production rate jointly reducing and balancing human workloads and ergonomic risk within acceptable limits. Results show the models capacity to identify optimal job rotation schedules jointly achieving productivity and ergonomic risk goals. Performances of the solutions obtained improve as workforce flexibility increases. However, the study was focused on highly repetitive activities and did not consider electrical engineering non-repetitive complex tasks.

\section{Research Methodology}

Research methodology can be referred to as the universal technique the investigator utilizes to conduct a research project and the methodological strategy the researcher finds best suitable to resolve the research problem (Leedy \& Ormrod, 2013). Also, research methodology involves more than just knowing applicable research techniques suitable to a study but rather the justification underlying the rationale for the choice of research technique (Kothari, 2008). As a result, this procedure usually presents the researcher with new knowledge and an in-depth understanding of the behaviour of variables under study and factors of influence relative to the research problem (Sekaran \& Bougie, 2013).

Research Objectives: The objectives indicate the goals of a research study (Creswell, 2014). With that in mind, the objectives of this study are as follows:

- To measure the influence of multi-skilling on the flexibility of project scheduling

- To evaluate the relationship between multi-skilling and project labour costs

- To study the effect of multi-skilling on the duration of the project

- To evaluating multi-skilling and adoption of multi skills

- To evaluate the use of job redesign to facilitate workforce multi-skilling

Research Hypothesis: Hypothesis statements are predictions made by the researcher about expected results findings (Creswel, 2014). Therefore, the following are the research hypothesis statements:

H1: The use of multi-skilling provides for flexible project resource scheduling

H2: Multi-skilling has a positive effect on the project cost savings

H3: The use of multi-skilling has no significant impact on project duration

H4 (i): There is a positive relationship between multi-skilling and job redesign

H4 (ii): Multi-skilling has a positive impact on the adoption of multi-skills.

Population: Sekaran and Bougie (2013) define a study population as a group of individual elements or people or events of interest to the researcher to investigate and draw inferences accordingly. The population of this study is made up of eighty (80) X PTM Central Group project execution staff members. This means the total number of employees who meet the criteria for recruitment to this study, targeted recruits range from technical engineering employees to project support services and project management. 
Sampling Method: Simple random sampling method was used as the sampling method, because each unit included in the target population has equal chance of inclusion in the sample. Moreover, this method is assumed to counter bias during sample element selection. Establishing an optimal sample size for a study ensures adequate control to detect statistical significance. An exaggerated number of participants in a study is not only expensive but also unnecessarily increases the number of subjects to process. On the other hand, if a study experiences under-participation, it becomes statistically inconclusive and therefore incomplete (Suresh \& Chandrashekara, 2012). A 95\% confidence interval and 5\% level of significance was used to calculate the required sample size for the research study, confidence level means the amount of tolerable uncertainty and level of significance means the acceptable margin of error.

The Research Instruments: A quantitative research investigation makes use of surveys, experiments and questionnaires, to collect data that is revised and numerically presented to allow for data to be categorized using of statistical analysis. In other words, a quantitative researcher measures variables on a sample of elements to show the relationship between variables with the use of effect statistics such as correlations, relative frequencies and or differences between means; this is done with a focus on testing of theory (Antwi \& Hamza, 2015). A survey design provides a quantitative description of tendencies, attitudes or opinions of a population by examining a sample of the population in question and from the sample findings researchers generalize or induce inferences about the population. Similarly, in an experiment the researcher can also use a sample and generalize to the population, however; an experimental design is intended to test the impact of treatment on the results outcome thereby controlling all other possible influences to that outcome (Creswel, 2014). And, a questionnaire is a pre-formulated written set of questions to which research study respondents record their answers, usually within rather closely defined alternatives (Sekaran \& Bougie, 2013).

The principles of questionnaire design focus on the wording of the questionnaire, on how variables are categorized, scaled and coded, and lastly the presentation of the questionnaire in terms of appearance (Sekaran \& Bougie, 2013). Additionally, to encourage respondents to complete the questionnaire it must be kept as short as possible including questions themselves, it must be clearly worded and definition of concepts where necessary must be provided, it must begin with demographic questions to get respondents started and comfortable, follow appropriate use of measurement scales such dichotomous, Likert scales, etc., avoid openended questions if not intended for the study, avoid using leading questions as that influences respondents to respond towards a particular answer, take time to administer questionnaire pilot testing to uncover potential problems, and finally consider whether collection of data is for interval or nominal variable and a type of statistical technique intended for the study whether descriptive or inferential (Render, et al., 2015). A designed electronic questionnaire was constructed for the use of collecting data from research participants in a structured manner that allows for optimal addressing of the research purpose, hypothesis statements and overall research objectives in order to answer the research question.

Procedure for Data Collection: A designed electronic questionnaire was distributed to all participants of the study, collected and captured through the use of statistical software technologies; Question pro. Projected period of data collection was four weeks and during this phase a four-stage process was followed. Firstly, an email with an overview of the study, rights of participation and anonymity was sent out to all the respondent recruits. Secondly, the link to the administered electronic questionnaire was sent. Thirdly, during the collection period of data a follow-up email was sent to encourage participation. And lastly, a notification to thank respondents for their participation was sent. Notably, is the use of a higher confidence interval and or lower level of significant results in larger sample sizes ("Sample size calculator," 2016). Using a sample size calculator, a sample size of 67 was computed adequately representative of the total population of 80 elements.

Data Analysis and Interpretation: Accordingly, Creswell (2014) explains that descriptive data analysis studies the mean scores, standard deviations and range. Also, essential to keep in mind, is that in quantitative research studies where the process of data analysis ends with descriptive analysis, the study respondents' may have been too small for further inferential statistical analysis. The data collection software platform used was Question pro, an electronic questionnaire was designed, distributed to all research respondents, response data was collected by the tool automatically and a response report was created. Lastly, all statistical analysis was conducted using STATA, a statistical software tool. 
Reliability and Validity: The research study instrument validity allows for the accurate and consistent collection of data (Saunders, et al., 2009). Furthermore, sources used in the study were all credible in terms of peer review, published textbooks, online/internet sources were kept below five percent in references and sources were mostly limited to age in existence that is eighty percent of the sources kept to less than five years since publish. The use of the electronic data collection and analysis ensures the validity of data. Cronbach's alpha is a most used technique to test the reliability of a research instrument by testing internal consistency across various items in the research questionnaire. Cronbach's alpha (Cronbach 1951) assesses the reliability of a summative rating (Likert 1932) scale composed of specified items. Cronbach's alpha measures internal consistency, that is, how closely related a set of items are as a group (Tavakol \& Dennick, 2011).

Ethical Considerations: Ethics in business research is defined as an expected standard social code of conduct that rules norms of behaviour while conducting research. Also, ethical conduct applies to systems of government, organizations and stakeholders that sponsor the research, the researcher conducting the research and the respondents (Sekaran \& Bougie, 2013). The gatekeeper letter was obtained from X PTM Central Group manager for permission to conduct an academic research study prior to electronic questionnaire distribution. All recruits for participation were over the age of eighteen, no monetary incentive for participation, rights for participation was explained and emphasis was made that each respondent' can quit the study at any time without a consequence or penalty. The questionnaire was designed not to discriminate against research participants, sponsors and those interested to the research. In the informed consent form of the study the above ethical considerations were clearly explained and only after accepting the terms the electronic questionnaire allowed participants to engage with the study. Lastly, participation to the study is kept and will remain anonymous, and the electronic questionnaire data is safely stored and confidential for five years in line with the University of Kwa-Zulu Natal research policy.

\section{Analysis and Interpretation}

This Analysis and Interpretation focus on the analysis of data, presentation and interpretation of the response results and findings of the study. The respondents' response results are presented by means of figures and tables. The presentation of the results commences with the demographical information of the respondents followed by factors of project execution resource scheduling flexibility, project labour costs and duration of projects in response to workforce multi-skilling and the use of job redesign as a strategy to facilitate multiskilling. This is then tailed by the presentation of the results according to the objectives and hypotheses of the study.

Table 1: Personal Demographic Information

\begin{tabular}{lllclclc}
\hline Variable & Label & Male & \multicolumn{3}{c}{ Female } & \multicolumn{3}{c}{ Total } \\
& & Freq. & Perc & Freq. & Perc & Freq. & Perc \\
\hline Race & African & 26 & 76.5 & 14 & 87.5 & 40 & 80.0 \\
& Indian & 8 & 23.5 & 2 & 12.5 & 10 & 20.0 \\
Total & & 34 & 100.0 & 16 & 100.0 & 50 & 100.0 \\
Age group & 21 to 30 years & 10 & 29.4 & 7 & 43.8 & 17 & 34.0 \\
& 31 to 40 years & 19 & 55.9 & 9 & 56.3 & 28 & 56.0 \\
Total & 41 to 50 years & 5 & 14.7 & 0 & - & 5 & 10.0 \\
Job grade & & $\mathbf{3 4}$ & $\mathbf{1 0 0 . 0}$ & $\mathbf{1 6}$ & $\mathbf{1 0 0 . 0}$ & $\mathbf{5 0}$ & $\mathbf{1 0 0 . 0}$ \\
& T11 & 9 & 27.3 & 7 & 43.8 & 16 & 32.7 \\
& T12 & 15 & 45.5 & 5 & 31.3 & 20 & 40.8 \\
Total & T13 & 5 & 15.2 & 1 & 6.3 & 6 & 12.2 \\
Experience & S\&M Band & 4 & 12.1 & 3 & 18.8 & 7 & 14.3 \\
& & $\mathbf{3 3}$ & $\mathbf{1 0 0 . 0}$ & $\mathbf{1 6}$ & $\mathbf{1 0 0 . 0}$ & $\mathbf{4 9}$ & $\mathbf{1 0 0 . 0}$ \\
& $\mathbf{5}$ Years & 11 & 33.3 & 5 & 31.3 & 16 & 32.7 \\
Total & $\mathbf{6 - 1 0}$ Years & 11 & 33.3 & 8 & 50.0 & 19 & 38.8 \\
& $\mathbf{1 1}-\mathbf{1 5}$ Years & $\mathbf{7}$ & 21.2 & 3 & 18.8 & 10 & 20.4 \\
& $>\mathbf{1 5}$ years & 4 & 12.1 & 0 & - & 4 & 8.2 \\
& & $\mathbf{3 3}$ & $\mathbf{1 0 0 . 0}$ & $\mathbf{1 6}$ & $\mathbf{1 0 0 . 0}$ & $\mathbf{4 9}$ & $\mathbf{1 0 0 . 0}$ \\
\hline
\end{tabular}




\begin{tabular}{|c|c|c|c|c|c|c|c|}
\hline \multicolumn{8}{|c|}{$\begin{array}{c}\text { Journal of Economics and Behavioral Studies (ISSN: 2220-6140) } \\
\text { Vol. 10, No. 4, pp. 235-251, August } 2018 \\
\end{array}$} \\
\hline \multirow[t]{2}{*}{ Education levels } & Diploma/equivalent & 18 & 54.5 & 11 & 68.8 & 29 & 59.2 \\
\hline & Degree/ equivalent & 15 & 45.5 & 5 & 31.3 & 20 & 40.8 \\
\hline Total & & 33 & 100.0 & 16 & 100.0 & 49 & 100.0 \\
\hline \multirow[t]{2}{*}{ Professional body } & Yes & 23 & 69.7 & 7 & 43.8 & 30 & 61.2 \\
\hline & No & 10 & 30.3 & 9 & 56.3 & 19 & 38.8 \\
\hline Total & & 33 & 100.0 & 16 & 100.0 & 49 & 100.0 \\
\hline
\end{tabular}

Table 1 indicates that eight out of ten respondents (80\%) were African, while two out of ten (20\%) were Indian. Comparably, there were more males than females thus $68 \%$ to $32 \%$ respectively. Twenty-eight respondents (56\%) were aged 31-40 years, a third (34\%) were aged 21-30 years with a few (10\%) who were aged 41-50 years. Proportionally, females were more likely (43.8\%) to be aged 21-30 years compared to males (29.4\%). There were no significant differences in the percentage of male (55.9\%) and female (56\%) respondents aged 31-40 years. Notably, there were no female respondents aged $41-50$ years. Four out of ten (40.8\%) respondents were in the T12 (senior technician) job grade, a third (33\%) were T11 (junior technician) while a few (19\%) were in S\&M (specialist and management) job band, and very few (12\%) were in T13 (senior supervisor) job grade. Male respondents were more likely (45.5\%) to be in T12 job grade than females (31.2\%), while females were more likely to be in T11 job grade compared to males (43.85 vs. 27.3\%). Almost four out of ten (39\%) had between six to eight years work experience; a third with less than 5 years' experience, and a fifth (20\%) with 11-15 years of experience. Very few respondents (8\%) with over 15 years of work experience and were all males. Notably, females were more likely (50\%) to have 6-10 years of work experience than males $(33 \%)$ respectively. Regarding education levels, six out of ten (59\%) respondents had a diploma or equivalent qualifications; while four out of ten (40\%) had degrees. Females were more likely (69\% vs. 55\%) to have diplomas compared to males. Six in ten (61.2\%) respondents belonged to a professional body; while 39\% did not. Male respondents were much more likely $(70 \%)$ to belong to a professional body compared to females $(44 \%)$.

Descriptive Statistics: A Likert-type question (or 'item') asked respondents to select one of five responses that are ranked in order of strength. The following section provides descriptive statistics in the form of frequencies for the Likert scale responses for the different subscales. Each section on frequency tables is followed by descriptive statistics which provide mean scores and standard deviations. The scores were computed to produce mean scores that represent the strength along the 1-5 scale standard deviations indicate how far the values are away from the mean value, while skewness quantifies symmetricity of data distribution.

Table 2: Descriptive Statistics Summary - Project scheduling Flexibility Statistics

\begin{tabular}{llllll}
\hline $\mathbf{3}$ system missing values & $\mathbf{N}$ & $\mathbf{M e a n}$ & $\mathbf{S t d}$. Dev & Min & Max \\
\hline $\begin{array}{l}\text { Workforce multi-skilling helps cushion against unforeseen } \\
\text { project schedule changes. }\end{array}$ & 47 & 1.68 & 0.783 & 1 & 4 \\
$\begin{array}{l}\text { Multi-skilled workforce helps improve project labour } \\
\text { resource availability. }\end{array}$ & 47 & 1.55 & 0.717 & 1 & 4 \\
$\begin{array}{l}\text { The use of multi-skilled workforce could smoothen } \\
\text { rescheduling of labour resources from one project to } \\
\text { another in multiple project environments such as X PTM. }\end{array}$ & 1.55 & 0.686 & 1 & 4 \\
$\begin{array}{l}\text { Multi-skilled workforce improves project labour resource } \\
\text { utilization }\end{array}$ & & 1.53 & 0.747 & 1 & 4 \\
\hline
\end{tabular}

Table 2 shows that all aspects of schedule flexibility had mean scores greater than 1 but less than 2 . This indicates respondents' tendency to generally agree on all four aspects pertaining to project schedule flexibility. The standard deviation (the spread of the distribution of the variable) for all factors is less than 1 , this indicates that there were no outliers in responses. Multi-skilled workforce helps improve project labour resource utilization (Mean score $=1.5$ ) was the highest rated in terms of the agreement, even though not significantly different from the other three factors. 
Journal of Economics and Behavioral Studies (ISSN: 2220-6140)

Vol. 10, No. 4, pp. 235-251, August 2018

Table 3: Descriptive Statistics Summary- Multi-Skilling and Project Costs Statistics

\begin{tabular}{|c|c|c|c|c|c|}
\hline 3 missing system values & $\mathbf{N}$ & Mean & Std. Dev & Min & Max \\
\hline $\begin{array}{l}\text { Multi-skilled workforce lack of skill specialization can drive up project } \\
\text { costs by means of defects resulted due to lack of expert knowledge. }\end{array}$ & 47 & 2.28 & 1.155 & 1 & 4 \\
\hline $\begin{array}{l}\text { Multi-skilled workforce strategy will help X PTM Central Group } \\
\text { reduce project transport costs }\end{array}$ & 47 & 1.83 & 0.916 & 1 & 4 \\
\hline $\begin{array}{l}\text { The use of multi-skilled workforce can help cut project labour costs } \\
\text { for X PTM Central Group by reducing the number of labour workforce } \\
\text { required per project. }\end{array}$ & 47 & 1.57 & 0.715 & 1 & 4 \\
\hline $\begin{array}{l}\text { Provided that a multi-skilled employee begins a project from start to } \\
\text { finish, the experience gained from the whole project can help provide } \\
\text { critical input feedback on lessons learnt and possible ways to reduce } \\
\text { costs on future projects. }\end{array}$ & 47 & 1.49 & 0.621 & 1 & 4 \\
\hline
\end{tabular}

The highest rated factor (agreement) was that provided that a multi-skilled employee begins a project from start to finish, the experience gained from the whole project could help provide critical input feedback on lessons learnt and possible ways to reduce costs on future projects (Mean score $=1.5$ ). The lowest rated factor (mild agreement) was that Multi-skilled workforce lack of skill specialization could drive up project costs by means of defects resulted due to lack of expert knowledge (Mean score=2.3). A skill ranking system should be developed to trace skill gaps and areas of improvement to sustain adoption of multi-skilling as a strategy at X PTM Central Group and increase talent pool without having to increase headcounts.

Table 4: Descriptive Statistics Summary - Multi-skilling and project duration statistics

\begin{tabular}{llllll}
\hline $\mathbf{4}$ missing system values & $\mathbf{N}$ & Mean & Std. Dev & Min & Max \\
\hline $\begin{array}{l}\text { The use of multi-skilled workforce will not reduce job } \\
\text { activity duration because the job is not performed by } \\
\text { specialist personnel. }\end{array}$ & & 2.61 & 1.125 & 1 & 5 \\
$\begin{array}{l}\text { Multi-skilled workforce utilization allows project } \\
\text { managers control over activity sequencing meaning } \\
\text { rearrangement of tasks to suit project timelines or targets. }\end{array}$ & 1.78 & 0.629 & 1 & 4 \\
$\begin{array}{l}\text { Multi-skilled workforce tends to take longer to finish an } \\
\text { activity, but the time lost on activity duration compensates } \\
\text { for idle time that a specialist would have spent waiting for } \\
\text { the next specialist job (specialist idle time cost). }\end{array}$ & & & & & \\
\end{tabular}

The use of multi-skilled workforce will not reduce job activity duration because the job is not performed by specialist personnel was the least rated factor in terms of the agreement (Mean score equals 2.6) towards uncertainty. Multi-skilled workforce utilization allows project managers control over activity sequencing meaning the rearrangement of tasks to suit project timelines and targets was the highly rated factor (Mean score equals 1.8) agreement.

Table 5: Descriptive Statistics Summary: The effect of adopting multi-skilling strategy statistics

\begin{tabular}{|c|c|c|c|c|c|}
\hline & $\mathbf{N}$ & Mean & Std. Dev & Min & Max \\
\hline $\begin{array}{l}\text { X PTM Central Group project resources are adequately } \\
\text { qualified (educated) in their respective field of specialisation. }\end{array}$ & 46 & 1.74 & 0.648 & 1 & 3 \\
\hline $\begin{array}{l}\text { X PTM Central Group project resources are competent in terms } \\
\text { of skills, technical knowledge, experience and proficiency in the } \\
\text { execution of projects. }\end{array}$ & 45 & 1.76 & 0.743 & 1 & 4 \\
\hline $\begin{array}{l}\text { Project management resources can negotiate project scope, } \\
\text { time, cost and quality effectively with clients to meet in-house } \\
\text { business objectives. }\end{array}$ & 45 & 1.84 & 0.767 & 1 & 4 \\
\hline $\begin{array}{l}\text { X PTM Central Group project resources demonstrate } \\
\text { knowledge in the execution of activities. }\end{array}$ & 46 & 1.85 & 0.842 & 1 & 4 \\
\hline
\end{tabular}




\begin{tabular}{lllllll}
\hline $\begin{array}{l}\text { Project management resources are effective at managing risks } \\
\text { from both financial and technical standpoints. }\end{array}$ & 1.87 & 0.625 & 1 & & 4 \\
$\begin{array}{l}\text { Project Support Services show extensive experience in } \\
\text { managing projects. }\end{array}$ & 2.17 & 0.950 & 1 & & 5 \\
$\begin{array}{l}\text { However, project resources cannot perform activities across } \\
\text { disciplines because departments are divided into specialist } \\
\text { skills e.g. Protection, Tele-control, and Metering. }\end{array}$ & 2.18 & 1.173 & 1 & & 5 \\
\hline
\end{tabular}

X PTM Central Group project resources are adequately qualified (educated) in their respective field of specialisation together with X PTM Central Group project resources demonstrate knowledge in the execution of activities were the highest rated factors (Mean scores of 1.7) of the agreement. The two lowest rated (relative) were that (i) Project Support Services show extensive experience in managing projects, and that (ii) However, project resources cannot perform activities across disciplines because departments are divided into specialist skills e.g. Protection, Tele-control, and Metering (Mean score of 2.17 and 2.18).

Table 6: Descriptive Statistics Summary - Practical Means to Facilitate Multi-skilling

\begin{tabular}{llllll}
\hline & $\mathbf{N}$ & Mean & Std. Dev & Min & Max \\
\hline $\begin{array}{l}\text { To support multi-skilling over and above on-job training and } \\
\text { job rotation, managers can to set aside an adequate training }\end{array}$ & 42 & 1.52 & 0.671 & 1 & 4 \\
$\begin{array}{l}\text { budget for project resources to attend technical training on } \\
\text { specific equipment }\end{array}$ & & & & & \\
$\begin{array}{l}\text { On-job training can be used to facilitate multi-skilling at X } \\
\begin{array}{l}\text { PTM Central Group } \\
\text { After on job training, job rotation can be used as one of the }\end{array}\end{array}$ & 42 & 1.62 & 0.623 & 1 & 4 \\
other means to help facilitate multi-skilling. & & 0.623 & 1 & 4 \\
\hline
\end{tabular}

All the practical means to facilitate multi-skilling at X PTM Central Group mean scores indicate general agreement amongst respondents. To support multi-skilling over and above on-job training and job rotation, managers can to set aside an adequate training budget for project resources to attend technical training on specific equipment was the highest rated factor (Mean score of 1.5), while After on job training, job rotation can be used as one of other means to help facilitate multi-skilling was the least rated (Mean score=1.6).

Reliability of Data: When using Likert-type scales it is very important to measure Cronbach's alpha coefficient for internal consistency reliability of scales (Creswell, 2014). Cronbach's alpha (Cronbach 1951) assesses the reliability of a summative rating (Likert 1932) scale composed of specified items. Cronbach's alpha measures internal consistency, that is, how closely related a set of items are as a group (Tavakol \& Dennick, 2011). Table 7 below indicates the results for all the Likert scale questions.

Table 7: Internal Consistency Reliability Test

\begin{tabular}{lllllll}
\hline & & & item-test & item-rest & Inter-item & \\
\hline $\begin{array}{l}\text { Objectives } \\
\begin{array}{l}\text { Influence of multi-skilled } \\
\text { workforce on project scheduling }\end{array}\end{array}$ & SCHEDULE & 47 & 0.756 & 0.609 & 0.133 & $\mathbf{0 . 8 1 5}$ \\
$\begin{array}{l}\text { flexibility } \\
\begin{array}{l}\text { Relationship between multi- } \\
\text { skilling and project cost savings }\end{array}\end{array}$ & & & & & \\
$\begin{array}{l}\text { Effect of multi-skilling on project } \\
\text { duration }\end{array}$ & DURATION & 46 & 0.582 & 0.362 & 0.155 & $\mathbf{0 . 8 6 8}$ \\
$\begin{array}{l}\text { Effect of adopting multi-skilling } \\
\text { strategy at X }\end{array}$ & MULTISKILL & 45 & 0.649 & 0.494 & 0.152 & $\mathbf{0 . 8 3 7}$ \\
$\begin{array}{l}\text { Adoption of multi-skilling at X } \\
\text { Job redesign }\end{array}$ & $\begin{array}{l}\text { ADOPTION } \\
\text { unstandardized items }\end{array}$ & 42 & 0.865 & 0.791 & 0.120 & $\mathbf{0 . 7 8 0}$ \\
\hline
\end{tabular}


The reviewed literature shows that results with an alpha coefficient of greater than 0.6 are very reliable and provide enhanced interpretation (Sekaran \& Bougie, 2013). The alpha coefficient for all the items was 0.84 , this indicates that the questions in the designed electronic questionnaire instrument asked what they were intended to ask and provided reliable results for inferential statistics in the multivariate analysis.

Spearman's Correlation: The Spearman rank order correlation is a nonparametric association measure of the strength and direction observed between two variables of a study. Also, the correlation coefficient ranges from -1 to +1 , the measurement of 0 indicates no correction, -1 shows a strongest negative correlation, whilst +1 shows a strongest positive correlation (Zaid, 2015). The following table provides results for the association between the dependent and the independent variables. At a statistical significance level of $5 \%$.

Table 8: Spearman's' Rank Correlation

\begin{tabular}{lllllll}
\hline & MULTIS L & SCHEDULE & COSTS & DURATION & ADOPTION & JOB \\
\hline MULTISKILL & 1 & & & & & \\
SCHEDULE & 0.2872 & 1 & & & \\
Two-tailed sig & 0.0558 & & & & \\
COSTS & 0.3586 & 0.5776 & 1 & & \\
Two-tailed sig & 0.0156 & 0 & & & \\
DURATION & 0.3483 & 0.2569 & 0.3255 & 1 & \\
Two-tailed sig & 0.019 & 0.0848 & 0.0273 & & \\
ADOPTION & 0.5464 & 0.6755 & 0.6418 & 0.3132 & 1 & \\
Two-tailed sig & 0.0002 & 0 & 0 & 0.0434 & & \\
JOB & 0.4445 & 0.6022 & 0.7553 & 0.2846 & 0.7909 & 1 \\
Two-tailed sig & 0.0032 & 0 & 0 & 0.0677 & 0 & \\
\hline
\end{tabular}

Table 8 above indicates that there are statistically significant associations between the different factors of the multi-skilled workforce on the flexibility of project resource scheduling and project costs. Multi-skilling has weak positive association with flexibility of project resource scheduling $\left(\mathrm{r}_{\mathrm{s}}=0.3 ; \mathrm{p}<0.05\right)$, moderate association with project costs $\left(\left(\mathrm{r}_{\mathrm{s}}=0.36 ; \mathrm{p}<0.05\right)\right.$, duration $\left(\mathrm{r}_{\mathrm{s}}=0.35 ; \mathrm{p}<0.05\right)$, strong associations with adoption $\left(\mathrm{r}_{\mathrm{s}}=0.5\right.$; $\mathrm{p}<0.05)$ and job redesign $\left(\mathrm{r}_{\mathrm{s}=0.44 ;} \mathrm{p}<0.05\right)$. The results imply that an increase in multi-skilling is likely to improve project scheduling, costs, duration, and job redesign to facilitate multi-skilling. Stronger positive associations, with statistically significant results are seen among project cost and schedule flexibility $\left(\mathrm{r}_{\mathrm{s}=} 0.6\right.$; $\mathrm{p}<0.05)$, schedule flexibility and adoption $\left(\mathrm{r}_{\mathrm{s}=0.7} ; \mathrm{p}<0.05\right)$ as well as schedule flexibility and job redesign $\left(\mathrm{r}_{\mathrm{s}=}=0.7\right.$; $\mathrm{p}<0.05)$. Further strong positive associations occur between adoption and project costs $\left(\mathrm{r}_{\mathrm{s}=0.6}\right.$; $\left.\mathrm{p}<0.05\right)$, job redesign and project costs $\left(r_{s}=0.75 ; p<0.05\right)$ and, job redesign and adoption $\left(r_{s}=0.8 ; p<0.05\right)$. An increase in schedule flexibility, adoption strategies and job redesign is likely to contribute positively to project costs.

Hypothesis Testing: This section examines the relationship between the factors of the multi-skilled workforce on project scheduling flexibility and project costs through paired t-tests for paired observations. This is done through four hypothesis tests. Specifically, the independent samples t-test compares the difference in the means from two groups to a given value, Stat a calculate the t-statistic and its p-value under the assumption that the sample comes from an approximately normal distribution. Hypothesis statements are predictions made by the researcher about expected results findings (Creswel, 2014). Therefore, the following are the research hypothesis statements:

Hypothesis 1: a relationship exists between multi-skilled workforce and project resource scheduling flexibility

Table 9: Paired t-test: multi-skilled workforce and project resource scheduling flexibility

\begin{tabular}{llcrrrc}
\hline Variable code & Obs & Mean & Std. Err. & Std. Dev. & [95\% Conf. & Interval] \\
\hline MULTISKILL & 45 & 1.91 & 0.072 & 0.483 & 1.763 & 2.053 \\
SCHEDULE & 45 & 1.61 & 0.083 & 0.558 & 1.438 & 1.773 \\
Diff & 45 & 0.30 & 0.093 & 0.624 & 0.115 & 0.490 \\
\hline
\end{tabular}


Mean (diff) $=$ mean (MULTISKILL - SCHEDULE), $\mathrm{t}=3.3 \operatorname{Pr}(|\mathrm{T}|>|\mathrm{t}|)=0.002$, The results indicate that there is a positive (0.30) difference between the means of multi-skilled workforce and project resource scheduling flexibility, the $p$-value associated with the t-test is statistically significant at $5 \%$ level $(p<0.05)$. Hence, the null hypothesis (Ho: mean (diff) $=0$ ) is rejected. A conclusion can therefore be made that there is a direct relationship between the two variables. The $t$-statistics $(t=3.3)$ suggests the use of multi-skilled workforce provides for flexible project resource scheduling as much as 3.3 times.

Hypothesis 2: Multi-skilling a has a positive effect on the project cost savings

Table 10: Paired t-test: multi-skilled workforce and project cost savings

\begin{tabular}{lllllll}
\hline Variable & Obs & Mean & Std. Err. & Std. Dev. & [95\% Conf. & Interval] \\
\hline MULTISKILLED & 45 & 1.908 & 0.072 & 0.483 & 1.763 & 2.053 \\
COSTS & 45 & 1.773 & 0.077 & 0.515 & 1.619 & 1.928 \\
Diff & 45 & 0.135 & 0.084 & 0.565 & -0.035 & 0.304 \\
\hline
\end{tabular}

Mean (diff) $=$ mean (MULTISKILL - COSTS) $t=1.59 \operatorname{Pr}(|\mathrm{T}|>|\mathrm{t}|)=0.1174$, The results indicate that there is negligible a positive $(0.13)$ difference between the means of multi-skilled workforce and project costs, the $\mathrm{p}$ value associated with the t-test is not statistically significant at $5 \%$ level $(\mathrm{p}>0.05)$. Hence, the null hypothesis (Ho: mean $($ diff $)=0$ ) is not rejected. A conclusion can therefore be made that there is probably no positive relationship between multi-skilled workforce and project costs savings.

Hypothesis 3: The use of multi-skilling has no significant impact on project duration

Table 11: Paired T-Test: Multi-Skilled Workforce and Project Duration

\begin{tabular}{|c|c|c|c|c|c|c|}
\hline Variable code & Obs & Mean & Std. Err. & Std. Dev. & [95\% Conf. & Interval] \\
\hline MULTIS L & 45 & 1.91 & 0.072 & 0.483 & 1.763 & 2.053 \\
\hline DURATION & 45 & 2.22 & 0.091 & 0.607 & 2.040 & 2.405 \\
\hline Diff & 45 & 0.31 & 0.094 & 0.630 & 0.504 & 0.125 \\
\hline
\end{tabular}

Mean (diff) $=$ mean (MULTISKILL - DURATION) $\mathrm{t}=-3.34 \operatorname{Pr}(|\mathrm{T}|>|\mathrm{t}|)=0.0017$, The results indicate that there is a negative (0.31) difference between the means of multi-skilled workforce and project duration, the p-value associated with the $t$-test is statistically significant at $5 \%$ level $(\mathrm{p}<0.05)$. Hence, the null hypothesis (Ho: mean (diff) $=0$ ) is rejected. A conclusion can therefore be made that there is no positive relationship between multiskilled workforce and duration. In other words, the use of multi-skilling has 3.3 times the negative significant impact on project duration.

Hypothesis 4 (i): There is a positive relationship between multi-skilled workforce and adoption of multiskilling

Table 12: Paired T-Test: Multi-Skilled Workforce and Adoption of Multi-Skills

\begin{tabular}{|c|c|c|c|c|c|c|}
\hline Variable code & Obs & Mean & Std. Err. & Std. Dev. & [95\% Conf. & Interval] \\
\hline MULTIS L & 42 & 1.898 & 0.074 & 0.482 & 1.748 & 2.048 \\
\hline ADOPTION & 42 & 1.635 & 0.082 & 0.530 & 1.470 & 1.800 \\
\hline diff & 42 & 0.263 & 0.075 & 0.484 & 0.112 & 0.414 \\
\hline
\end{tabular}

Mean (diff) $=$ mean (MULTISKILL - ADOPTION) $t=3.52 \operatorname{Pr}(|\mathrm{T}|>|\mathrm{t}|)=0.0011$, The results above indicate that there is a positive (0.26) difference between the means of multi-skilled workforce and adoption of the multiskills, the $p$-value associated with the t-test is highly statistically significant at $5 \%$ level $(p<0.05)$. Hence, the null hypothesis (Ho: mean (diff) $=0$ ) is rejected. A conclusion can therefore be made that there is a positive 
relationship between multi-skilled workforce and adoption of multi-skills. In other words, the use of multiskilling could have 3.5 times the positive significant impact on multi skills adoption rate.

Hypothesis 4(ii): There is a positive relationship between multi-skilling job redesign

Lastly, the research provides scientific results findings and analysis procedure used to draw up conclusions about the effect of using multi-skilling on project resource scheduling, project cost savings, project duration, adoption of multi-skills and the influence of job redesign in facilitating multi-skilling.

Table 13: Paired T-Test: Multi-Skilled Workforce and Job Redesign

\begin{tabular}{llrrrrc}
\hline Variable & Obs & \multicolumn{1}{c}{ Mean } & Std. Err. & Std. Dev. & [95\% Conf. & Interval] \\
\hline MULTIS L & 42 & 1.90 & 0.074 & 0.482 & 1.748 & 2.048 \\
JOB & 42 & 1.59 & 0.079 & 0.514 & 1.427 & 1.748 \\
Diff & 42 & 0.31 & 0.081 & 0.526 & 0.147 & 0.475 \\
\hline
\end{tabular}

Mean (diff) $=$ mean (MULTISKILL - JOB) $\mathrm{t}=3.8 \operatorname{Pr}(|\mathrm{T}|>|\mathrm{t}|)=0.0004$, The results above indicate that there is a positive (0.31) difference between the means of multi-skilled workforce and job redesign, the $p$-value associated with the t-test is highly statistically significant at $5 \%$ level $(\mathrm{p}<0.05)$. Hence, the null hypothesis (Ho: mean (diff) $=0$ ) is rejected. A conclusion can therefore be made that there is a positive relationship between multi-skilled workforce and job redesign. In other words, the use of multi-skilling could have 3.8 times the positive significant impact on job redesign.

\section{Conclusion and Recommendations}

This research contributes knowledge to project engineering management effective staffing of teams and operations management. The arrangement of the research objectives was a carefully thought out exercise to allow for research results to be quantified and generalized to the research site to enhance business decision making. Academic and or business researchers can use this research to further study the concept of multiskilling and its impact in engineering projects, since the most literature on multi-skilling covers the retail sector, moderate on the construction industry and very few in project engineering management.

Objective 1: Influence of Multi-Skilled Workforce on Project Scheduling Flexibility: The conducted descriptive statistics showed that multi-skilled workforce could have an influence on project scheduling flexibility, but the results could not be used alone to draw conclusions. Accordingly, Spearman's correlation of associations was conducted, and the results showed that the use of multi-skilled workforce to have a weak positive association with project scheduling flexibility. However, correlations alone cannot be used to generalize results findings of a sample. Therefore, a conducted paired t-test hypothesis test concluded that the use of multi-skilled workforce provides for flexible project resource scheduling as much as 3.3 times. In other words, at X PTM Central Group the use of multi-skilled workforce can have up to 3.3 times more influence on project resource scheduling flexibility.

Objective 2: Evaluating the Relationship between Multi-Skilling and Project Costs: The descriptive statistics results in this regard showed that majority of respondents were in agreement with all the factors in this objective. Spearman's correlation results of association showed a moderate association between the two variables. Conclusively, paired t-test hypothesis results suggested a non-positive relationship between the two variables. This means the use of multi-skilling at X PTM Central Group will probably have no influence on project cost savings.

Objective 3: Evaluating the Effect of Multi-Skilling on Project Duration: A majority of respondents were in agreement that the use of multi-skilled workforce has an influence on project duration. The correlation results of association indicated a moderate positive association between the variables. A paired $t$-test hypothesis made 
the conclusion that there is no positive relationship between the use of multi-skilled workforce and project duration. The results conclude that the use of multi-skilled workforce at X PTM Central Group has no positive relationship with project duration.

Objective 4: Evaluating the Effect of Adopting Multi-Skilling Strategy: The majority of respondents in this regard were also in agreement that multi-skilling has an influence on the adoption of skills. The correlation results of association indicated a strong positive association between the two variables. Using hypothesis results, a conclusion was made that there is a positive relationship between multi-skilled workforce and adoption of multi-skills. This can be translated; the use of multi-skilling at X PTM Central Group has a positive effect on the adoption of multi-skills.

Objective 5: Evaluating the Use of Job Redesign to Facilitate Workforce Multi-Skilling: A large number of respondents were also in agreement with the factors of job redesign to facilitate workforce multi-skilling at $\mathrm{X}$ PTM Central Group. The results of associations showed a strong association between the variables. Hypothesis testing provided a conclusion that there is a positive relationship between multi-skilled workforce and job redesign. This concludes that at X PTM Central Group job redesigned can be used to facilitate multi-skilling.

Conclusion: There is evidence that the use of multi-skilled workforce provides for flexible project resource scheduling as much as 3.3 times. There is probably no positive relationship between multi-skilled workforce and project costs. Further results indicate that use of multi-skilling has 3.3 times the negative significant impact on project duration. The use of multi-skilling could have 3.8 times the positive significant impact on job redesign. Lastly, the use of multi-skilling could have 3.5 times the positive significant impact on the adoption of multi-skilling.

Limitations of the Study: There were no major problems encountered during this research, except for the usual research associated challenges such as ethical clearance application which took longer than anticipated by the research study timelines. The other challenge was the response rate at the beginning of the study, there was a low response rate but after a follow-up email respondents' participation increased greatly. However, a total number of non-responses was 17 , in other words $25 \%$ of the recruits did not participate to the study. The size of the sample was limited by the research site population, that is X PTM Central Group project execution personnel, meaning the views were only limited to this group and no opinions from other $\mathrm{X}$ divisions were factored. The study assumed that all respondents have basic project execution and technical backgrounds, since employees at research site are technical personnel by profession.

Recommendations: The researched concluded that multi-skilled workforce has a positive influence on project scheduling flexibility at X PTM Central Group. However, it is recommended for this business unit to pay more attention to the factor "workforce multi-skilling helps cushion against unforeseen project schedule changes" as it showed to be in contrast with other contributing factors to the flexibility of project scheduling. X PTM Central Group should improve on the idea that, multi-skilled workforce lack of skill specialization can drive up project costs by means of defects resulted due to lack of expert knowledge, and that multi-skilled workforce strategy will help X PTM Central Group reduce project transport costs to yield positive results from multi-skilling and project cost savings objective. It imperative for X PTM Central Group to search for alternative ways to equip multi-skilled employees to reduce activity job duration to relatively close to a specialist output level and centralize multi-skilling to help afford project managers better control of projects, as this will improve multiskilling influence to reduce project duration. Assessment to project labor resources showed that there is a need for project support services to show more experience and professionalism in managing projects, to improve proficiency in project management. It is recommended that technical project labor resources must be afforded a platform to practice cross skilling perhaps by doing away with specialist departments and rather form a multiskilled talent pool. 


\section{References}

Abomeh, O. \& Peace, N. (2015). Effects of Training on Employees' Productivity in Nigeria Insurance Industry. British Journal of Economics, Management \& Trade, 7(3), 227-235.

Abotaleb, I., Moussa, M. \& Hussain, S. (2014). Optimization of Allocating Multi-Skilled Labor Resources Using Genetic Algorithms. Halifax, CSCE 2014 General Conference.

Acock, A. C. (2014). A Gentle Introduction to Stata. 4 ed. College Station: TX: Stata Press.

Adamu, N., Nensok, M. \& Aka, A. (2012). Multi-skilling Barriers in The Construction Industry in North-Western Nigeria. Abuja, West Africa Built Environment Research (WABER) Conference.

Adeyoyin, S. et al. (2015). Effects of Job Specialization and Departmentalization on Job Satisfaction among the Staff of a Nigerian University Library, Lincoln: University of Nebraska.

Afifi, A. M. S. \& Clark, V. (2012). Practical multivariate analysis. 5 ed. Boca Raton: CRC Press.

Ahmadian Fard Fini, A., Rashidi, T., Akbarnezhad, A. \& Travis Waller, S. (2016). Incorporating Multiskilling and Learning in the Optimization of Crew Composition. Journal of Construction Engineering and Management, 142(5).

Akinola, J., Ogunsemi, D. \& Dada, M. (2015). Impact of Multiskilling On Competency of Nigerian Quantity Surveyors. Abuja, The Nigerian Institute of Quantity Surveyors.

Aliyu, A. A., Bello, M. U., Kasim, R. \& Martin, D. (2014). Positivist and Non-Positivist Paradigm in Social Science Research: Conflicting Paradigms or Perfect Partners? Journal of Management and Sustainability, 4(3), 79-95.

Anon. (2015). Project Planning and Scheduling Using PERT and CPM Techniques with Linear Programming: Case Study. International Journal of Scientific \& Technology Research, 4(8), 222-227.

Antwi, S. K. \& Hamza, K. (2015). Qualitative and Quantitative Research Paradigms in Research: A Philosophical Reflection. European Journal of Business and Management, 7(3), 217-225.

Arunadhevi, P. (2016). Optimization of Construction Project Scheduling by Using Linear Programming. International Journal of Advanced Research Trends in Engineering and Technology, 3(2), 1268-1273.

Attia, E., Duquenne, P. \& Le-Lann, G. (2013). Considering skills evolutions in multi-skilled workforce allocation with flexible working hours. International Journal of Production Research, 52(15), 4548-4573.

Brown, A., Adams, J. \& Amjad, A. (2007). The relationship between human capital and time performance in project management: A path analysis. International Journal of Project Management, 25(2007), 77-89.

Burleson, R., Haas, C., Tucker, R. \& Stanley, A. (1998). Multi-skilled Labor Strategies in Construction. ASCE Journal of Construction Engineering and Management, 124(6), 480-489.

Chan, K. (2014). Multiple project team membership and performance: empirical evidence from engineering project teams. Sajems special issue, 17(2014), 76-90.

Creswel, J. (2014). Research design: qualitative, quantitative, and mixed methods approach. 4 ed. London: SAGE Publications Ltd.

Creswell, J. (2014). Research design: qualitative, quantitative, and mixed methods approach. 4 ed. London: SAGE Publications Ltd.

Das, K. R. \& Imon, R. A. H. M. (2016). A Brief Review of Tests for Normality. American Journal of Theoretical and Applied Statistics, 5(1), 5-12.

DeVaro, J. \& Farnham, M. (2010). Two Perspectives on Multiskilling and Product Market Volatility, East Bay: Economic and Social Research Council.

Dickson, O. (2003). A pilot investigation of the Potential Impact of the Practical Design and Implementation of Multi-Skilling to optimise Employees and achieve improved Productivity within the Automobile Manufacturing Industry., Durban: University of KwaZulu Natal.

Ernst A, T., Jiang, H., Krishnamoorthy, M. \& Sier, D. (2004). Staff scheduling and rostering: A review of applications, methods and models. European Journal of Operational Research, 153, 3-27.

X. (2014). Deliver Projects - Programme Management Procedure, Johannesburg: s.n.

X. (2016). Engineering Cost Control on Capital Projects Works Instruction, Johannesburg: s.n.

Gomar, J., Haas, C. \& Morton, D. (2012). Assignment and Allocation Optimization of Partially Multi skilled Workforce. Journal of Construction Engineering and Management, 128(2), 103-108.

Hegazy, T., Shabeeb, A., Elbeltagi, E. \& Cheema, T. (2000). Algorithm for Scheduling with Multi skilled Constrained Resources. Journal of Construction Engineering and Management, 126 (6), 414-421. 
Heimerl, C. \& Kolisch, R. (2010). Work assignment to and qualification of multi-skilled human resources under knowledge depreciation and company skill level targets. International Journal of Production Research, 48(13), 3759-3781.

Horbury, C. \& Wright, M. (2010). Development of a Multiskilling Life Cycle Model, Norwich: Health and Safety Executive.

Irene, L., 2009. Multiskilling in construction - a strategy for stable employment. Technological and Economic Development of Economy, 15(4), 540-560.

Jaskowski, P. (2013). Scheduling Construction Projects with Multi-Skilled Resources. International Journal of Arts \& Sciences, 6(3), 347-353.

Kagona, J., Shukla, J. \& Oduor, J. (2015). The effect of employee training on project performance A case of the Girl Child Catch up project of the International Education Exchange. Journal of Marketing and HR, 1(1), 33-40.

Kaymaza, K. (2010). The Effects of Job Rotation Practices on Motivation: A Research on Managers in the Automotive Organizations. Business and Economics Research Journal, 1(3), 69-85.

Keller, G. (2012). Managerial Statistics Abbreviated. 9th ed. UK/Europe/Middle East/Africa: South-Western Cengage Learning.

Kepha, O., Assumptah, K. W. \& Dismaso, 0. (2014). The Influence of Training and Development on the Performance of Employees in Research Institutes in Kenya. International Journal of Science and Research, 3(5), 139-146.

Kim, J., Kang, C. \& Hwang, I. (2012). A practical approach to project scheduling: considering the potential quality loss cost in the time-cost tradeoff problem. International Journal of Project Management, 30, 264-272.

Kothari, C. (2008). Research Methodology: Methods \& Techniques. 2 ed. New Delhi: New Age International (P) Ltd.

Kuhn, T. S. (2012). The structure of scientific revolutions, Chicago: University of Chicago Press.

Lee, B. \& Nam, J. (2013). What drives Korean firms to downsize under the global financial crisis? Asian Pacific Business Review, 19(2), 171-185.

Leedy, P. \& Ormrod, J. (2013). Practical Research Planning and Design. 10 ed. New York: Pearson Education Inc.

Lill, I. (2009). Multiskilling in Construction a Strategy for Stable Employment. Technological and Economic Development of Economy, 15(4), 540-560.

Liu, S. \& Wang, C. (2012). Optimizing linear project scheduling with multi-skilled crews. Automation in Construction, 24, 16-23.

Long, J. S. \& Freese, J. (2014). Regression Models for Categorical Dependent Variables Using Stata. 3 ed. College Station: TX: Stata Press.

Mackey, A. \& Gass, S. M. (2016). Second Language Research: Methodology and Design. 2nd ed. New York: Routledge Taylor and Francis Group.

Makholwa, A. (2010). Ageing Workforce a Worry. Finweek, 24 June.

Mateus, A. D., Allen-Ile, C. \& Iwu, C. (2014). Skills Shortage in South Africa: Interrogating the Repertoire of Discussions. Mediterranean Journal of Social Sciences, 5(6), 63-68.

Maylor, H. (2010). Project management. 4 ed. Harlow: Pearson Education Limited.

Mir, F. A. \& Pinnington, A. H. (2014). Exploring the value of project management: Linking Project Management Performance and Project Success. International Journal of Project Management, 32, 202-217.

Morita, H. (2005). Multi-skilling, Delegation and Continuous Process Improvement: A Comparative Analysis of US-Japanese Work Organizations. Economica, 72, 69-93.

Mossa, G. et al. (2016). Productivity and ergonomic risk in human-based production systems: A job-rotation scheduling model. International Journal of Production Economics, 171(4), 471-477.

Motsoeneng, L., Schultz, C. \& Bezuidenhout, A. (2013). Skills Needed by Engineers in the Platinum Mining Industry in South Africa, Pretoria: Mining Qualifications Authority, South Africa.

Nwaogazie, I., Augustine, O. \& Henshaw, T. (2016). Multi-skilling in construction industry and dual skill labour strategy: a case of construction companies in port harcourt. International Journal of Civil Engineering and Technology, 7(4), 208-222.

Puttick, G. (2008). Multi-skilling overcomes labour shortages. Analysis management, 14 March, p. 1.

Qin, S., Liu, S. \& Kuang, H. (2016). Piecewise Linear Model for Multiskilled Workforce Scheduling Problems considering Learning Effect and Project Quality. Mathematical Problems in Engineering, 11. 
Rajendra, J. (2016). Accountability of Multi-Skilling in Enrichment of Career Planning of Organization and Employee in the Global Scenario, India: MIT- SOM PGRC KJIMRP National Research Conference.

Render, B., Stair, R., Hanna, M. \& Hale, S. (2015). Quantitative Analysis for Management. 12 ed. Harlow: Pearson Education Limited.

Saravani, S. R. \& Abbasi, R. (2013). Investigating the influence of job rotation on performance by considering skill variation and job satisfaction of bank employees. Tehnički vjesnik, 20(3), 473-478.

Saunders, M., Lewis, P. \& Thornhill, A. (2009). Research methods for business students. 5 ed. Harlow: Pearson Education Ltd.

Sekaran, U. \& Bougie, R. (2013). Research methods for business. 6 ed. West Sussex: Wiley and Sons Ltd.

Singh, V. \& Shah, S. (2014). Implementing Kaizen in A Job Shop Industry Through Multi-Skilling of Labour. International Journal of Emerging Technology and Advanced Engineering, 4(3), 289-291.

Srinivasan, I. A. (2014). The impact of multi-skilling on an outsourced environment. International Journal of Advance Research, 2(1), 1-18.

Stratton, S. J. (2015). Assessing the Accuracy of Survey Research. Prehospital and Disaster Medicine; Cambridge, 30(3), 225-226.

Suresh, K. \& Chandrashekara, S. (2012). Sample size estimation and power analysis for clinical. Journal of Human Reproductive Sciences, 5 (1), 7-12.

Sushil, S. (2014). Role of Job Enrichment and Job Enlargement in Work-Life Balance. Global Journal of Finance and Management, 6(3), 239-244.

Tancott, G. (2014). Addressing the skills shortage. Infrastructure News and Service Delivery, 14 May.

Tarus, B. K. (2014). Effects of Job Rotation Strategy on High-Performance Workplace, in Lake Victoria North Water Services Board, Kenya. International Journal of Business and Management, 9(11), 139-146.

Tavakol, M. \& Dennick, R. (2011). Making sense of Cronbach's alpha. International Journal of Medical Education, 2(2011), 53-55.

Testa, B. (2010). Multi-skilled Employees Sought as Versatility Becomes a Workplace Virtue. workforce, 20 September, 1-3.

Zaid, M. A. (2015). Correlation and Regression Analysis. 1 ed. Ankara: The Statistical, Economic and Social Research and Training Centre for Islamic Countries.

Zar, J. (2014). Spearman Rank Correlation, Illinois: Research Gate.

Zha, H. \& Zhang, L. (2014). Scheduling Projects with Multi-skill Learning Effect. The Scientific World Journal, 2014(731081), 7. 